\title{
Matematiği Öğrenmenin Matematik Öğretmenlerinin Görüşleri
} Doğrultusunda İncelenmesi

\section{An Investigation of Mathematics Learning in the Views of Mathematics Teachers}

\author{
Ebru Kükeyl \\ Tayfun Tutak ${ }^{2}$
}

Alıntılama: Kükey, E. \& Tutak, T. (2019). Matematiği öğrenmenin matematik öğretmenlerinin görüşleri doğrultusunda incelenmesi. Ulusal Eğitim Akademisi Dergisi (UEAD), 3(1), 84-95.

Geliş tarihi:

26 Şubat 2019

Kabul tarihi:

23 Mart 2019

(C) UEAD 2019

Tüm saklıdir.

Received:

26 February 2019
Özet: $\mathrm{Bu}$ çalışmada ortaokul matematik öğretmenlerinin matematiği öğrenmeye yönelik görüşlerinin incelenmesi amaçlanmıştır. $\mathrm{Bu}$ kapsamda çalışma, öğretmenlerin görüşlerinin ayrıntılı olarak incelenebilmesi için nitel araştırma yönetmelerinden durum çalışması olarak tasarlanmıştır. Çalışma grubunu 46 ortaokul matematik öğretmeni oluşturmaktadır. Gönüllü katılım doğrultusunda öğretmenlerle yapılandırılmış görüşmeler yapılmış ve elde edilen veriler içerik analizi ile analiz edilmiştir. Analizler doğrultusunda veriler belirli temalara ayrılmıştır. Analizler sonucunda matematiği öğrenmenin özellikleri; günlük yaşam, ders ögretimi, zihinsel etkinlikler ve kişisel gelişim olmak üzere 4 tema altında hakları belirlenmiştir. Belirlenen temalardan günlük yaşam temasında en çok ifade edilen özelliğin, matematiği günlük yaşamda kullanma ifadesinin yer aldığ 1 belirlenmiştir. Ders öğretimi temasında, bilimin gelişmesine katkı sağlama ifadesi çoğunlukla kullanılmıştır. Zihinsel etkinlikler teması kapsamında, mantıklı düşünme kavramının ön plana çıktığı tespit edilmiştir. Kişisel gelişim temasında ise farkındalık kazandırma, insanı olgunlaştırma, iletişim kurabilme, farklı görüşlere saygılı davranma gibi özelliklerinin ifade edildiği sonucuna ulaşılmıştır. Sonuç olarak matematik öğretiminde konuların günlük yaşamla ilişkilendirilmesi gerektiğinin, matematik etkinliklerinin zihinsel aktiviteleri geliştirdiğinin ve matematik öğretmen ve öğretmen adaylarının bu bilinçte eğitim almalarının gerekli olduğu düşünülmektedir.

Anahtar kelimeler: matematiği öğrenme, matematik öğretimi, matematik öğretmenleri.

Abstract: In this study, it is aimed to examine the opinions of middle school mathematics teachers about learning mathematics. In this context, the study is designed as a case study from the qualitative research management in order to examine the teachers' views in detail. The study group consisted of 46 middle

\footnotetext{
${ }^{I}$ (Sorumlu yazar) Arş.Gör.Dr., Fırat Üniversitesi, Eğitim Fakültesi, Matematik ve Fen Bilimleri Eğitimi Bölümü, ekukey@firat.edu.tr, ORCID ID: 0000-0002-2130-0884.

${ }^{2}$ Dr.Öğr.Üyesi, Firat Üniversitesi, Eğitim Fakültesi, Matematik ve Fen Bilimleri Eğitimi Bölümü tayfuntutak@hotmail.com,ORCID ID: 0000-0002-0277-6377.
} 
Matematiği öğrenmenin, matematik öğretmenlerinin görüşleri doğrultusunda incelenmesi

Accepted:

23 March 2019

(C) UEAD 2019

All rights reserved. school mathematics teachers. In line with the voluntary participation, structured interviews were conducted with the teachers and the data were analyzed with content analysis. As a result of the analyzes, the properties of learning mathematics are expressed under 4 themes: daily life, lesson teaching, mental activities and personal development. In the theme of daily life, it was determined that the most expressed feature was the use of mathematics in daily life. In the theme of lesson teaching, the expression of contributing to the development of science was mostly used. It is determined that the concept of logical thinking comes to the forefront in the context of mental activities. In the theme of personal development, it was concluded that awareness raising, human maturation, communication, and respect for different opinions were expressed. As a result, it is thought that mathematics teaching should be related to daily life, mathematics activities develop mental activities and mathematics teachers and teacher candidates should be educated in this consciousness.

Keywords: learning mathematics, teaching mathematics, mathematics teachers.

\section{Giriş}

Matematik sayıları, cebiri, işlemleri, orantıyı, geometriyi, alan hesaplamayı ve daha pek çok konuyu öğretirken yapısı nedeniyle tahminde bulunmayı, akıl yürütmeyi ve örüntüleri keşfetmeyi de öğretmektedir (Umay, 2003). Bunun yanında sayı, nokta ve küme gibi soyut kavramlar arasındaki ilişkileri anlamayı da hedeflemektedir (Yıldırım, 2014).

Matematik öğretimi bireye günlük hayatta gerekli olan matematiksel bilgi ve becerileri kazandırmayı, problem çözmeyi öğretmeyi, günlük hayattaki olaylara problem çözme çerçevesinde bakabilmeyi kazandırmayı hedeflemektedir (Altun, 2001). Bu kapsamda matematik öğretiminin iki önemli amacının olduğu ifade edilmektedir. İlk olarak matematik okuryazarı olan bir toplum oluşturarak teknolojinin, sanayinin ve günlük yaşamdaki diğer alanlardaki eleman ihtiyacına yönelik bireyler yetiştirmektir. İkinci olarak ise akademik olarak matematikle ilgilenecek bireyleri küçük yaşlardan itibaren yetiştirerek, onları birer matematik bilimcisi olarak topluma kazandırmaktır (Baki, 2006).

Etkili matematik öğretimi öğrencilerin neler bildiklerini, neleri öğrenmeye ihtiyaçları olduğunu anlamayı ve öğrencileri öğrenmelerine yönelik teşvik edip desteklemeyi gerektirir (NCTM, 2000). Bu kapsamda matematik eğitimi öğrencilere deneyimlerini açıklayabilecekleri, analiz edebilecekleri, tahminde bulunabilecekleri, problem çözebilecekleri dil ve sistematiği kazandırır. Ayrıca çeşitli matematiksel durumların olduğu ortamların oluşturulmasıyla öğrencilerin akıl yürütme becerilerinin gelişmesini sağlar (MEB, 2006). 
Matematik eğitiminde öğretmenler kritik öneme sahip olup öğrenci başarısında öğretmen niteliği oldukça önemlidir. Öğretmenler matematiksel kavramlara yönelik derin anlamlar oluşturmalı, öğrettikleri matematiksel kavramları derinlemesine bilmeli, anlamalı ve yaptıkları etkinliklerde aktif bir şekilde kullanmalıdırlar (NCTM, 2000). Ayrıca hazırlamış oldukları etkinlik ve öğrenme ortamlarını geliştirmek için matematik öğretimi sırasında öğrencilerin öğrenme güçlüklerinin farkında olmaları gerekmektedir (Yetkin, 2003). Bu kapsamda matematik öğretimine yönelik olarak çeşitli çalışmalar yapılmıştır (Grant, 1984; Muijs \& Reynolds, 2001; Stipek, Givvin, Salmon \& MacGyvers, 2001; Kükey \& Aslaner, 2017). Bu nedenle yapılan bu çalışmada matematiği öğrenmenin, ortaokul matematik öğretmenlerinin görüşleri doğrultusunda incelenmesi amaçlanmıştır. Bu doğrultuda matematik öğretmenlerinin matematiği öğrenmenin ne anlama geldiğine yönelik olarak görüşleri incelenmiştir.

\section{Yöntem}

Yapılan çalışmada matematik öğretmenlerinin düşüncelerinin ayrıntılı olarak incelenmesi amaçlandığından, araştırmanın yöntemi nitel araştırma yöntemlerinden durum çalışma olarak tasarlanmıştır. Durum çalışmalarının belirgin özelliği bir ya da birkaç durumun ayrıntılı olarak derinlemesine incelenmesidir. Bu kapsamda bir duruma yönelik etkenler bütüncül olarak araştırılmakta ve araştırılan durumu nasıl etkiledikleri ve bu durumdan nasıl etkilendikleri üzerinde durulmaktadır (Yıldırım \& Şimşek, 2011).

\section{Çalışma Grubu}

Araştırmanın çalışma grubu amaçlı örnekleme kapsamında kolay ulaşılabilir örnekleme yöntemi ile belirlenmiştir. Bu doğrultuda 46 ortaokul matematik öğretmeni araştırmanın çalışma grubunu oluşturmaktadır. Gönüllü katılım doğrultusunda çalışmaya katılan matematik öğretmenlerine ait bilgiler aşağıdaki tabloda verilmiştir.

Tablo1. Öğretmenlerin Özellikleri

\begin{tabular}{ccc}
\hline Cinsiyet & Frekans & Yüzde \\
\hline Kadın & 35 & 76,1 \\
Erkek & 11 & 23,9 \\
\hline Toplam & 46 & 100 \\
\hline
\end{tabular}


Tablo incelendiğinde araştırmaya katılan öğretmenlerin 35 'inin kadın olduğu ve çalışma grubunun \%76,1'ini temsil ettiği görülmektedir. Ayrıca 11 öğretmenin ise erkek olduğu ve çalışma grubunun \%23,9’unu temsil ettiği belirlenmiştir.

\section{Veri Toplama Araçları ve Verilerin Analizi}

Öğretmenlerin görüşlerini ayrıntılı bir şekilde belirlemek amacıyla görüşme formu hazırlanmıştır. Bu form aracılığıyla matematik öğretmenlerinin matematiği öğrenmeye yönelik görüşleri belirlenmeye çalışılmıştır. Bu formda "Matematiği öğrenmeyi nasıl açıklarsınız?" şeklinde açık uçlu bir soruyla öğretmenlerin görüşleri alınmıştır. Araştırma yapılmadan önce 4 matematik öğretmeniyle görüşmeler yapılmış ve bu görüşmeler aracılığıyla sorulan sorunun kapsamı, görüşmelerin süresi ve araştırmacının deneyim kazanması sağlanmıştır. Gerekli düzenlemeler sonrası öğretmenlerle asıl çalışma yapılmıştır. Görüşmeler sırasında öğretmenlerin görüşlerinin gizli tutulacağı ifade edilmiştir.

Görüşmeler sonrasında elde edilen veriler, içerik analizi ile incelenmiştir. İçerik analizi, birbirine benzeyen verilerin incelenip belirli tema ve kavramlar kapsamında bir araya getirilmesi ve okuyucuların anlayabileceği bir şekilde yorumlanması olarak ifade edilir (Yıldırım \& Şimşek, 2011). Veriler analiz edilirken öğretmenler Ö1, Ö2, Ö3 ... şeklinde kodlanmıştır. Verilerin analizi aşamasında veriler iki bağımsız araştırmacı tarafından kodlanarak kodlamalar arasındaki uyum düzeyi incelenmiştir. $\mathrm{Bu}$ doğrultuda elde edilen uyum düzeyi \%91 olarak belirlenmiştir. Araştırmacıların farklı olarak yapmış oldukları kodlamalar ise ortak görüş doğrultusunda değerlendirilmiştir.

\section{Bulgular}

Ortaokul matematik öğretmenleriyle yapılan görüşmelerden elde edilen bulgular doğrultusunda matematiği öğrenmenin özellikleri 4 tema altında belirlenmiştir. Belirlenen temalar; günlük yaşam, ders öğretimi, zihinsel etkinlikler ve kişisel gelişim olarak belirlenmiştir.

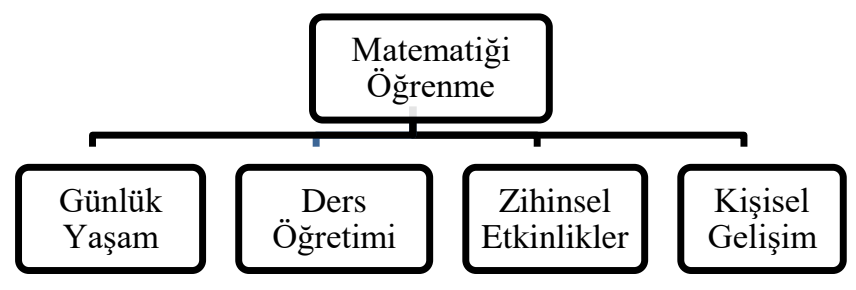

Şekil 1. Matematiği Öğrenme Alt Boyutlart 


\section{Günlük Yaşam Temasına Yönelik Bulgular}

“Günlük Yaşam” temasına yönelik olarak ortaokul matematik öğretmenlerinin ifade etmiş oldukları özelliklerden elde edilen kodlamalar aşağıdaki tabloda verilmiştir.

Tablo 2. Tema 1-Günlük Yaşam

\begin{tabular}{|c|c|c|}
\hline Özellikler & Öğretmenlerin Kodları & Frekans \\
\hline Günlük yaşamda kullanma & $\begin{array}{l}\text { Ö1, Ö4, Ö6, Ö7, Ö8, Ö9, Ö10, Ö11, Ö12, Ö13, Ö14, } \\
\text { Ö15, Ö16, Ö17, Ö20, Ö21, Ö22, Ö27, Ö30, Ö33, } \\
\text { Ö34, Ö35, Ö36, Ö42, Ö43, Ö44, Ö45 }\end{array}$ & 27 \\
\hline Evreni anlama & 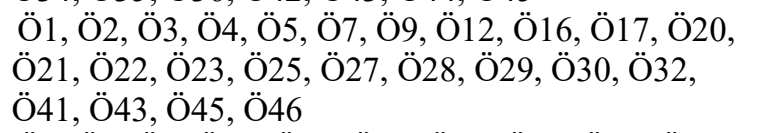 & 24 \\
\hline Her alanda yer alması & $\begin{array}{l}\text { Ö6, Ö8, Ö9, Ö11, Ö13, Ö22, Ö27, Ö34, Ö36, Ö39, } \\
\text { Ö40, Ö43, Ö44, Ö45, Ö46 }\end{array}$ & 15 \\
\hline Hayatı anlama & Ö3, Ö11, Ö17, Ö18, Ö19, Ö23, Ö26, Ö31, Ö40, Ö43 & 10 \\
\hline Günlük hayatı kolaylaștırma & Ö2, Ö11, Ö17, Ö27, Ö29, Ö30, Ö33, Ö45 & 8 \\
\hline Hayatı öğrenme & Ö6, Ö12, Ö24, Ö27, Ö34, Ö38, Ö39 & 7 \\
\hline Günlük yaşam problemlerini çözme & Ö3, Ö38, Ö39 & 3 \\
\hline Toplumun kalkınmasını sağlama & Ö4, Ö7, Ö36 & 3 \\
\hline Hayata bakış açısını değiştirme & Ö15, Ö36, Ö40 & 3 \\
\hline Pratik çözümler bulma & Ö22, Ö38 & 2 \\
\hline İnsanın çevresini tanımasını sağlama & Ö25, Ö29 & 2 \\
\hline Olayları anlama & Ö26, Ö32 & 2 \\
\hline Medeniyet & Ö10 & 1 \\
\hline İnsanın kendisini tanımasını sağlama & Ö25 & 1 \\
\hline Olayların farkında olma & Ö25 & 1 \\
\hline $\begin{array}{l}\text { Olayların birbirleriyle olan ilişkisini } \\
\text { anlama }\end{array}$ & Ö31 & 1 \\
\hline Olayları yorumlayabilme & Ö31 & 1 \\
\hline Geleceğe yönelik öngörü oluşturma & Ö1 & 1 \\
\hline
\end{tabular}

Öğretmenlerin matematiği öğrenmeye yönelik görüşleri incelendiğinde "günlük yaşam" teması altında en çok ifade edilen kavramın günlük yaşamda kullanma ifadesinin bulunduğu belirlenmiştir. Bunun yanında evreni anlama ve her alanda yer alma ifadelerinin de çoğunluk tarafından kullanıldığı tespit edilmiştir. Hayatı anlama, günlük yaşamı kolaylaştırma, hayatı öğrenme kavramları da sıklıkla kullanılmıştır. Ayrıca toplumun kalkınmasını sağlama, hayata bakış açısını değiştirme, insanın çevresini tanımasını sağlama, olayların birbiriyle olan ilişkisini anlama, olayları yorumlayabilme gibi özelliklerin de kullanıldığı görülmüştür. Bu doğrultuda bazı öğretmenlerin görüşleri şu şekildedir.

"Matematik sadece günlük hayatta alışveriş yaparken işimize yarayacak bir ders değildir. Bunun için matematik ögrenmek, matematik üzerinde derin düşünebilmek toplumun kalkınması adına bir başlangıç olabilir. ” (Ö4) 
Matematiği öğrenmenin, matematik öğretmenlerinin görüşleri doğrultusunda incelenmesi

"Matematiği öğrenmek, hayatı öğrenmektir. Giydiğimiz kıyafetten elimizdeki cep telefonlarına kadar her şeyi öğrenmektir. Kâinatın nasıl olduğunu ve anlamını öğrenmektir. Bir ăgaca baktı̆̆ımızda onun sadece gövde ve yapraklardan ibaret olmadı̆̆ını onunda bir altın oranının olduğunu bilmektir.” (Ö12)

"Matematiği öğrenmek hayata olan bakış açımızı da değiştirir. Çünkü hayatı farklı bir yönden görmemizi să̆lar.” (Ö36)

\section{Ders Öğretimi Temasına Yönelik Bulgular}

“Ders Öğretimi” temasına yönelik olarak ortaokul matematik öğretmenlerinin ifade etmiş oldukları özelliklerden elde edilen kodlamalar aşağıdaki tabloda verilmiştir.

Tablo 3. Tema 2-Ders Ö̆gretimi

\begin{tabular}{llc}
\hline Özellikler & Öğretmenlerin Kodlar1 & Frekans \\
\hline Bilimin gelişmesine katk1 sağlama & Ö4, Ö7, Ö18, Ö26, Ö35, Ö37, Ö39, Ö42 & 8 \\
Problem çözme yeteneği kazandırma & Ö1, Ö11, Ö26, Ö28, Ö35, Ö45 & 6 \\
Diğer derslerde başarıllı olmayı sağlama & Ö12, Ö24, Ö28, Ö45 & 4 \\
Soyut kavramları anlama & Ö4, Ö5, Ö17 & 3 \\
Sayllar arasındaki bağıntıy1 görme & Ö27, Ö31, Ö42 & 3 \\
Problemleri birden fazla yolla çözebilme & Ö15, Ö37, Ö45 & 3 \\
Teknolojinin gelişmesini sağlama & Ö18, Ö26, Ö28 & 3 \\
Somutlaştırabilme & Ö1, Ö3, Ö42 & 3 \\
Sayısal verileri öğrenme & Ö7, Ö35, Ö46 & 3 \\
Kavramları öğrenme & Ö1, Ö33 & 2 \\
Kavramlar1 sembollerle gösterebilme & Ö27, Ö35 & 2 \\
Sonuca ulaşabilme & Ö31 & 1 \\
Matematiğin nerelerde kullanıldığını anlama & Ö33 & 1 \\
Araştırma yapma & Ö19 & 1 \\
Sayların ahengini öğrenme & Ö3 & 1 \\
Çözüm odaklı olma & Ö46 & 1 \\
Ezbere bağl1 kalmama & Ö7 & 1 \\
Neyi ne için öğrendiğini bilme & Ö1 & 1 \\
İspat yapabilme & Ö1 & 1 \\
\hline
\end{tabular}

Matematiği öğrenmenin “ders öğretimi” teması kapsamında öğretmenlerin görüşleri incelendiğinde en çok bilimin gelişmesine katkı sağlama ifadesinin yer aldığı tespit edilmiştir. Bunun yanında problem çözme yeteneği kazandırma, diğer derslerde başarılı olmayı sağlama ifadelerinin de çoğunlukla kullanıldığı belirlenmiştir. Ayrıca soyut kavramları anlama, somutlaştırabilme, sonuca ulaşabilme, araştırma yapma, çözüm odaklı olma, kavramları öğrenme, teknolojinin gelişmesini sağlama, kavramları sembollerle gösterebilme, ispat yapabilme gibi özelliklerin de kullanıldığı görülmüştür. Bu doğrultuda bazı öğretmenlerin görüşleri şu şekildedir. 
“Matematik tüm bilimlerin temelini oluşturur. Matematiği öğrenince diğer

bilimler hakkında yorum yapabilir, mantık yürütebiliriz. ” (Ö37)

"Matematiği ögrenmek sayıların, rakamların kendi aralarındaki ilişkiyi

öğrenmektir. Kavramların sembollerle gösterilme biçimidir.” (Ö27)

“Matematik soyut nesneleri somutlaştırabilmeyi öğretir.” (Ö42)

\section{Zihinsel Etkinlikler Temasına Yönelik Bulgular}

"Zihinsel Etkinlikler" temasına yönelik olarak ortaokul matematik öğretmenlerinin ifade etmiş oldukları özelliklerden elde edilen kodlamalar aşağıdaki tabloda verilmiştir.

Tablo 4. Tema 3-Zihinsel Etkinlikler

\begin{tabular}{llc}
\hline Özellikler & Öğretmenlerin Kodlar1 & Frekans \\
\hline Mantıklı düşünme & Ö1, Ö19, Ö21, Ö26, Ö27, Ö31, Ö32, Ö35, Ö36, Ö41, & 12 \\
Neden-sonuç ilişkisini anlama & Ö42, Ö46 & 9 \\
Farklı bakış aç1sı kazandırma & Ö1, Ö3, Ö6, Ö7, Ö22, Ö25, Ö29, Ö30, Ö31 & 7 \\
Zihni geliştirme & Ö5, Ö9, Ö12, Ö15, Ö17, Ö29, Ö46 & 6 \\
Analitik düşünmeyi sağlama & Ö5, Ö8, Ö14, Ö16, Ö28, Ö39 & 5 \\
Tahminde bulunabilme & Ö1, Ö6, Ö22, Ö28, Ö46 & 4 \\
Elesstirel düšünmeyi sağlama & Ö15, Ö16, Ö31, Ö36 & 3 \\
Soyut düşünmeyi kazandırma & Ö6, Ö15, Ö36 & 3 \\
Üst düzey düşünme becerisi kazandırma & Ö5, Ö17, Ö19 & 3 \\
Nesnel düşünebilme & Ö14, Ö15, Ö16, Ö33 & 3 \\
Genelleştirme yapabilme & Ö14, Ö22 & 2 \\
Çözüm yolu arama & Ö3, Ö28 & 2 \\
Muhakeme gücü kazandırma & Ö30, Ö31 & 2 \\
Ak11 yürütebilme & Ö33, Ö42 & 2 \\
Sayısal düşünme & Ö35 & 1 \\
Analiz edebilme & Ö37 & 1 \\
Ayrınt1l düşünebilme & Ö42 & 1 \\
\hline
\end{tabular}

Zihinsel etkinlikler temasına yönelik olarak öğretmenlerin görüşleri incelendiğinde en çok olarak mantıklı düşünme özelliğinin bulunduğu belirlenmiştir. Ayrıca neden sonuç ilişkisini anlama, farklı bakış açısı kazandırma, zihni geliştirme özelliklerinin çoğunlukla kullanıldığı tespit edilmiştir. Bunun yanında tahminde bulunabilme, soyut düşünmeyi kazandırma, nesnel düşünebilme, genelleştirme yapabilme, çözüm yolu arama, muhakeme gücü kazandırma, analiz edebilme, ayrıntılı düşünebilme gibi özeliklerin de ifade edildiği belirlenmiştir. Bu doğrultuda bazı öğretmenlerin görüşleri şu şekildedir.

"Neden sonuç ilişkisi kurmamızı sağlar ve analitik düşünmeye katkı sağlar." 


\begin{abstract}
"Matematiği öğrenme mantıksal düşünebilmeyi ve olayların birbiriyle ilişkilerini mantık kuralları çerçevesinde düşünebilmeyi ve yorumlayabilmeyi ögrenmek demektir.” (Ö31)

"Matematikte teorik bilgilerimin yanında özgün ürünler oluşturabiliyor ve bunları gerekirse fikrim olamayan bir konuda kullanabiliyor ve akıl yürütebiliyorsam matematiği ögrenmiş sayarım.” (Ö33)
\end{abstract}

\title{
Kişisel Gelişim Temasına Yönelik Bulgular
}

"Kişisel Gelişim” temasına yönelik olarak ortaokul matematik öğretmenlerinin ifade etmiş oldukları özelliklerden elde edilen kodlamalar aşağıdaki tabloda verilmiştir.

Tablo 5. Tema 4-Kişisel Gelişim

\begin{tabular}{llc}
\hline Özellikler & Öğretmenlerin Kodları & Frekans \\
\hline Farkındalık kazandırma & Ö5, Ö24 & 2 \\
İnsanı olgunlaştırma & Ö5 & 1 \\
İletişim kurabilme & Ö14 & 1 \\
Farklı görüşlere saygılı davranma & Ö16 & 1 \\
İnsanın ufkunu açma & Ö16 & 1 \\
Ayrıcalık kazandırma & Ö24 & 1 \\
Kişiyi aktifleștirme & Ö38 & 1 \\
Anlaşlır açıklamalar yapabilme & Ö46 & 1 \\
\hline
\end{tabular}

Kişisel gelişim teması altında ifade edilen özelliklerin diğer temalara göre daha az olduğu belirlenmiştir. Bu kapsamda farkındalık kazandırma, insanı olgunlaştırma, iletişim kurabilme, farklı görüşlere saygılı davranma, insanın ufkunu açma, ayrıcalık kazandırma, kişiyi aktifleştirme ve anlaşılır açıklamalar yapabilme özelliklerinin ifade edildiği tespit edilmiştir. Bu doğrultuda bazı öğretmenlerin görüşleri şu şekildedir.

“Matematik insanı olgunlaştırır ve farkındalık kazandırır.” (Ö5)

"Matematiğin ufuk açıc yönü vardır. Öğrenilen üst düzey matematik insanın zihnini açmakta, daha geniş, daha derin ve de ufku açık şekilde düşünmeye yardımcı olur.” (Ö16)

"Matematiği öğrenmek, insanın pasif durumdan aktif duruma geçmesi demektir. Çünkü matematiği ögrenmenin bireyin bütün konulara daha aktif katılım göstermesine fayda sağlar." (Ö38) 


\section{Sonuç, Tartışma ve Öneriler}

Yapılan bu çalışmada, matematiği öğrenmenin ne anlam ifade ettiği ortaokul matematik öğretmenlerinin görüşleri doğrultusunda incelenmiştir. $\mathrm{Bu}$ kapsamda elde edilen bulgular doğrultusunda matematiği öğrenme; günlük yaşam, ders öğretimi, zihinsel etkinlikler ve kişisel gelişim olarak belirlenen 4 tema altında ifade edilmiştir.

Günlük yaşam teması altında en çok ifade edilen özelliğin matematiği günlük yaşamda kullanma özelliğinin bulunduğu tespit edilmiştir. $\mathrm{Bu}$ durumun matematiğin günlük yaşamla ilişkili olması nedeniyle matematiği öğrenmenin günlük yaşamdaki olaylara çözüm bulmada kolaylık sağlayacağı şeklinde ifade edilebilir. Galbraith ve Stillman (2006) ile Yenilmez ve Uysal (2007) da benzer olarak matematikle günlük yaşamın ilişkilendirilmesi gerektiğine vurgu yapmışlardır. Ayrıca evreni anlama, hayatın her alanında yer alma, hayatı öğrenme, günlük yaşamı kolaylaştırma, toplumun kalkınmasını sağlama, hayata bakış açısını değiştirme, insanın çevresini tanımasını sağlama, olayların birbiriyle olan ilişkisini anlama, olayları yorumlayabilme gibi özelliklerinin kullanıldı̆̆ sonucuna ulaşılmıştır. Burada matematiğin günlük yaşamda uygulama alanlarının geniş olması nedeniyle öğretmenlerin, matematiği öğrenmenin günlük yaşamdaki olayları anlama, çözme gibi konularda oldukça etkili olduğunu ifade ettikleri belirlenmiştir. Bu kapsamda matematiği öğretiminde konuların günlük yaşamla ilişkili olarak verilmesinin öğrencilerin öğrenmeleri açısından faydalı olacağı düşünülmektedir.

Ders öğretimi teması kapsamında en çok ifade edilen özelliğin bilimin gelişmesine katkı sağlama ifadesinin bulunduğu görülmüştür. Buradan matematiğin diğer bilimlerde çok sık kullanılması nedeniyle böyle bir sonucun ortaya çıktığı düşünülebilir. Ayrıca problem çözme yeteneği kazandırma, diğer derslerde başarılı olmayı sağlama, soyut kavramları anlama, somutlaştırabilme, sonuca ulaşabilme, araştırma yapma, çözüm odaklı olma, kavramları öğrenme, teknolojinin gelişmesini sağlama, kavramları sembollerle gösterebilme, ispat yapabilme gibi ifadelerin de kullanıldığı sonucuna ulaşılmıştır. Bu sonuçlar arasında çözüm odaklı olma ifadesine yönelik olarak Raymond (1997), öğretmenlere göre çözüm yolu yerine doğru çözüme ulaşmanın daha önemli olduğunu ifade etmiş̧ir. Umay ve Kaf (2005) ise matematik öğretiminde sürece odaklanılmasının önemli olduğu üzerinde durmuşlardır. Ayrıca DeRoche (1981) ve Margaret (2000), matematiğin soyut kavramlardan oluştuğunu ve somutlaştırılarak öğretimin yapılmasını vurgulamışlardır. Buradan öğretmenlerin alan bilgilerinin ve alana yönelik pedagojik 
Matematiği öğrenmenin, matematik öğretmenlerinin görüşleri doğrultusunda incelenmesi

bilgilerinin yeterli düzeyde olması gerektiği ifade edilebilir. Yapılan çalışmalarda da bu durumu destekler nitelikte sonuçlara ulaşılmıştır (Ball, 1990; Carpenter, Fennema \& Franke, 1996; Ma, 1999; Philipp, Thanheiser \& Clement, 2002). Bu sonuçlar doğrultusunda matematiği diğer bilimlerle ilişkisinin anlatılmasının, konuları diğer derslerle bağlantılı olarak anlatmaya özen gösterecek şekilde bir matematik öğretiminin yapılmasının oldukça faydalı olacağı düşünülmektedir.

Zihinsel etkinlikler teması kapsamında en çok ifade edilen özelliğin mantıklı düşünme olduğu tespit edilmişsir. Bunun nedeni olarak matematikte bulunan düzen ve sistematiğin bireyi bir bütün olarak olayları görüp mantık çerçevesinde düşünmeye yönelttiği şekilde ifade edilebilir. $\mathrm{Bu}$ özelliğin yanında neden sonuç ilişkisini anlama, farklı bakış açısı kazandırma, zihni geliştirme özelliklerinin çoğunlukla kullanıldığı tespit edilmiştir. Bunun yanında tahminde bulunabilme, soyut düşünmeyi kazandırma, nesnel düşünebilme, genelleştirme yapabilme, çözüm yolu arama, muhakeme gücü kazandırma, analiz edebilme, ayrıntılı düşünebilme gibi özelliklerin de belirtildiği sonucuna ulaşılmıştır. Genel olarak matematiksel etkinliklerin öğrencilerin zihinsel aktivitelerini geliştirdiği ve yorum yapıp olaylara farklı açıklardan bakabilme özelliklerini kazandırdığı söylenebilir.

Kişisel gelişim temasında ise ifade edilen özelliklerin farkındalık kazandırma, insanı olgunlaştırma, iletişim kurabilme, farklı görüşlere saygılı davranma, insanın ufkunu açma, ayrıcalık kazandırma, kişiyi aktifleştirme ve anlaşılır açıklamalar yapabilme olduğu sonucuna ulaşılmıştır. Buradan matematiksel etkinliklerde kullanılan özelliklerin aslında bireyin kişisel özelliklerini şekillendirmede oldukça etkili olduğu ifade edilebilir. Bu doğrultuda matematik öğretiminin önemine yönelik olarak matematik öğretmen ve öğretmen adaylarının bilinçlendirilmesinin etkili bir öğretim açısından oldukça faydalı olacağı düşünülmektedir.

Sonuç olarak matematiğin günlük yaşamdaki kullanımını göz önünde bulundurarak matematik öğretiminin yapılmasının öğrencilerin daha bilinçli bir şekilde yaşamlarını devam ettirmelerinde oldukça etkili olduğu düşünülmektedir. Bunun yanında matematiğin diğer bilimlerinin gelişmesinin etkilediği ve öğrencilerin diğer derslerde de başarılı olmalarını sağladığ tespit edilmiştir. Ayrıca öğrencilerin mantıklı düşünmelerini sağladığı ve farklı bakış açısı kazandırdığı gibi özellikler açısından günlük hayatlarını devam ettirmede oldukça etkili olduğu 
sonucuna ulaşılmıştır. Bu kapsamda öğretmenlerin bu bilinç çerçevesinde derslerini devam ettirmelerinin, öğrencilerin gelişim ve başarıları açısından önemli olduğu düşünülmektedir.

\section{Kaynakça}

Altun, M. (2001). İlköğretim 6, 7 ve 8. sinıflarda matematik öğretimi. Bursa: Alfa Yayıncılık.

Baki, A. (2006). Kuramdan uygulamaya matematik ĕgitimi. (3. Bask1). Trabzon: Derya Kitapevi.

Ball, D. L. (1990). The mathematical understandings that prospective teachers bring to teacher education. The Elementary School Journal, 90(4), 449-466.

Carpenter, T. P., Fennema, E. \& Franke, M. L. (1996). Cognitively Guided Instruction: A Knowledge Base for Reform in Mathematics Instruction. The Elementary School Journal, 97(1), 3-20.

DeRoche, E. F. (1981). An administrator's guide for evaluating programs and personnel. Boston: Allyn and Bacon, Inc.

Galbraith, P. \& Stillman, G. (2006). A framework for identifying student blockages during transitions in the modelling process. Zentralblatt für Didaktik der Mathematik, 38(2), 143162.

Grant, C. E. (1984). A study of the relationship between secondary mathematics teachers' beliefs about the teaching-learning process and their observed classroom behaviors (conceptions). Dissertation Abstracts International, 46(4), 919.

Kükey, E. \& Aslaner, R. (2017). İlköğretim matematik öğretmen adaylarının, iyi bir matematik öğretmeninin nasıl olması gerektiğine yönelik görüşlerinin incelenmesi. International $e$ Journal of Educational Studies (IEJES), 1 (1), 1-11.

Ma, L. (1999). Knowing and teaching elementary mathematics: Teachers' understanding of fundamental mathematics in China and the United States. Mahwah, NJ: Lawrence Erlbaum.

Margaret, M. B. (2000). Instructional materials development: A review of the IMD program. Past, Present, and Future. National Science Foundation, Arlington VA Directorate for Education and Human Resources.

Muijs, D. \& Reynolds, D. (2001). Teachers' beliefs and behaviors: What really matters? Journal of Classroom Interaction, 37(2), 3-15. 
Matematiği öğrenmenin, matematik öğretmenlerinin görüşleri doğrultusunda incelenmesi

National Council of Teachers of Mathematics (2000). Principles and standards for school mathematics. Reston, VA: Author.

Philipp R., Thanheiser, E. \& Clement, L. (2002). The role of a children's mathematical thinking experience in the preparation of prospective elementary school teachers. International Journal of Educational Research, 37, 195-210.

Raymond, A. M. (1997). Inconsistency between a beginning elementary school teacher's mathematics beliefs and teaching practice. Journal for Research in Mathematics Education, 28, 550-577.

Stipek, D. J., Givvin, K. B., Salmon, J. M. \& MacGyvers, V. L. (2001). Teachers' beliefs and practices related to mathematics instruction. Teaching and Teacher Education, 17, 213226.

Umay, A. \& Kaf, Y. (2005). Matematikte kusurlu akıl yürütme üzerine bir çalışma. Hacettepe Üniversitesi Eğitim Fakültesi, 28, 188-195.

Umay, A. (2003). Matematiksel muhakeme yeteneği. Hacettepe Üniversitesi Eğitim Fakültesi Dergisi, 24, 234-243.

Yenilmez, K. \& Uysal, E. (2007). İlköğretim öğrencilerinin matematiksel kavram ve sembolleri günlük hayatla ilişkilendirebilme düzeyi. On Dokuz Mayıs Üniversitesi Eğitim Fakültesi Dergisi, 24, 89-98.

Yetkin, E., (2003). Student difficulties in learning elementary mathematics, ERIC Clearinghouse for Science Mathematics and Environmental Education, Columbus, Ohio.

Yıldırım, A. \& Şimşek, H. (2011). Sosyal bilimlerde nitel araştırma yöntemleri (8. Baskı). Ankara: Seçkin Yayıncılık.

Y1ldırım, C. (2014). Matematiksel düşünme (10. basım). İstanbul: Remzi Kitabevi. 